\title{
Habit Formation: A Resolution of the Equity Premium Puzzle
}

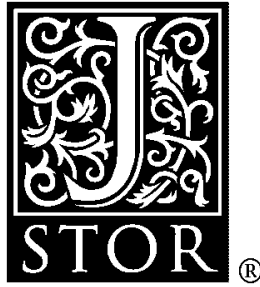

\author{
George M. Constantinides
}

The Journal of Political Economy, Vol. 98, No. 3. (Jun., 1990), pp. 519-543.

Stable URL:

http://links.jstor.org/sici?sici=0022-3808\%28199006\%2998\%3A3\%3C519\%3AHFAROT\%3E2.0.CO\%3B2-T

The Journal of Political Economy is currently published by The University of Chicago Press.

Your use of the JSTOR archive indicates your acceptance of JSTOR's Terms and Conditions of Use, available at

http://www.jstor.org/about/terms.html. JSTOR's Terms and Conditions of Use provides, in part, that unless you have obtained prior permission, you may not download an entire issue of a journal or multiple copies of articles, and you may use content in the JSTOR archive only for your personal, non-commercial use.

Please contact the publisher regarding any further use of this work. Publisher contact information may be obtained at http://www.jstor.org/journals/ucpress.html.

Each copy of any part of a JSTOR transmission must contain the same copyright notice that appears on the screen or printed page of such transmission.

The JSTOR Archive is a trusted digital repository providing for long-term preservation and access to leading academic journals and scholarly literature from around the world. The Archive is supported by libraries, scholarly societies, publishers, and foundations. It is an initiative of JSTOR, a not-for-profit organization with a mission to help the scholarly community take advantage of advances in technology. For more information regarding JSTOR, please contact support@ jstor.org. 


\section{Habit Formation: A Resolution of the Equity Premium Puzzle}

\section{George M. Constantinides}

University of Chicago and National Bureau of Economic Research

The equity premium puzzle, identified by Mehra and Prescott, states that, for plausible values of the risk aversion coefficient, the difference of the expected rate of return on the stock market and the riskless rate of interest is too large, given the observed small variance of the growth rate in per capita consumption. The puzzle is resolved in the context of an economy with rational expectations once the time separability of von Neumann-Morgenstern preferences is relaxed to allow for adjacent complementarity in consumption, a property known as habit persistence. Essentially habit persistence drives a wedge between the relative risk aversion of the representative agent and the intertemporal elasticity of substitution in consumption.

\section{Introduction}

Rational expectations, a cornerstone of modern theories in economics and finance, has come under attack. Are prices too volatile relative to the information arriving in the market? Is the mean premium on equities over the riskless rate too large? Is the real interest rate too low? Is the market's risk aversion too high? Is the intertemporal elasticity of substitution in consumption with respect to changes in the

Partial support for this project was provided by a National Science Foundation grant and by a gift to the Graduate School of Business, University of Chicago, by Dimensional Fund Advisors. I am grateful to Gary Becker, Fischer Black, Stephen Cecchetti, John Cochrane, Martin Eichenbaum, Wayne Ferson, Lars Hansen, Robert Lucas, Rajnish Mehra, Kevin M. Murphy, Dan Nelson, Ed Prescott, Ken Singleton, and Arnold Zellner for helpful comments. Expert computational assistance was provided by Ed Allen and Andrew Karolyi. I remain responsible for errors. 
productivity of capital too low? Finally, is the time series of aggregate consumption of nondurables and services too smooth?

Mehra and Prescott (1985) raised some of these questions in their equity premium puzzle. They employed a variant of Lucas's (1978) pure exchange economy and conducted a "calibration" exercise in the spirit of Kydland and Prescott (1982). Mehra and Prescott chose the parameters of the endowment process to match the sample mean, variance, and first-order autocorrelation of the annual growth rate of per capita consumption in the years $1889-1978$. They postulated that the representative agent has time- and state-separable utility. The puzzle is that they were unable to find a plausible pair of the subjective discount rate and relative risk aversion (RRA) of the representative agent to match the sample mean of the annual real rate of interest and of the equity premium over the same 90 -year period. Stated differently, the consumption growth rate appears to be too smooth to justify the mean equity premium.

The equity premium puzzle is not an isolated observation. Hansen and Singleton (1982, 1983), Ferson (1983), Grossman, Melino, and Shiller (1987), and several others rejected the Euler equation restriction on asset returns and the marginal rate of substitution implied by time- and state-separable preferences. Mankiw, Romer, and Shapiro (1985), Campbell and Shiller (1988), and West (1988a, 1988b) found that stock returns are too volatile if future dividends are discounted at a constant rate. Some of the empirical literature on the consumption function rejected the joint hypothesis of rationality and timeand state-separable preferences (see Deaton 1987; Hall 1989). Black (1986) and Roll (1988) questioned the rationality of price changes. Campbell and Kyle (1988) and De Long et al. (1990) made a case for noise traders. Finally, the stock market crash of October 1987 has added fuel to the debate.

The goal of this paper is to show that the equity premium puzzle is resolved in a rational expectations model, once we relax the time separability of preferences and allow for adjacent complementarity in consumption, a property known as habit persistence.

Marshall (1920) discussed the notion that tastes can be cultivated and that they are affected by past consumption. Duesenberry's (1949) thesis on the consumption function is probably the first serious examination of the implications of habit persistence. Ryder and Heal (1973) introduced the notion of adjacent and distant complementarity and discussed the stability of a growth model in the presence of habit persistence. Stigler and Becker (1977) argued that preferences should not be taken as exogenous but that it is fruitful to endogenize them and search for factors that explain differences or changes in behavior. Kydland and Prescott (1982) introduced preferences that are non- 
time separable in leisure. Becker and Murphy (1988) presented a theory of rational addiction and provided an insightful discussion on the link between addiction and complementarity. Sundaresan (1989) discussed the volatility of consumption and wealth in the presence of habit persistence.

In his examination of habit formation and dynamic demand functions, Pollak (1970, p. 761) insisted that "a fundamental assumption of the habit-formation model is that the individual does not take account of the effect of his current purchase on his future preferences and future consumption." I see nothing fundamental in the association of habit formation with some form of myopia or irrationality. In the present paper, habit persistence is introduced in a model with rational expectations, given that the goal is to show that the equity premium puzzle does not lead to the conclusion that the rational expectations model is bankrupt.

The paper is organized as follows. Habit persistence is embedded in a variant of the neoclassical growth model in Section II. Theorem 1 proves existence and uniqueness of an optimal policy and presents the optimal policy, the derived utility of capital, and the dynamics of capital and consumption. Theorem 2 derives the stationary distribution of the state variable and enables one to calculate the unconditional mean and variance of the consumption growth rate. Section IIC illustrates that the key role of habit persistence is to drive a wedge between the RRA coefficient and the inverse of the intertemporal elasticity of substitution in consumption. In Section III, I interpret the growth model as the equilibrium in a representative-consumer production economy. I resolve the equity premium puzzle by showing in table 1 that habit persistence can generate the sample mean and variance of the consumption growth rate with low risk aversion. In Section IV, I discuss alternative potential explanations of the puzzle. Finally, in Section V, I review related empirical evidence and offer suggestions for future research.

\section{Habit Persistence in a Production Economy}

\section{A. The Model and Assumptions}

Habit persistence is introduced in a variant of the neoclassical growth model. The optimal consumption and investment paths are interpreted as the equilibrium paths in a representative-consumer production economy, and the shadow prices of assets are interpreted as the equilibrium prices.

There exists only one production good, which is also the consumption good. This good may be consumed or invested in two tech- 
nologies. The technologies have constant returns to scale and rates of return over the period $[t, t+d t]$ equal to $r d t$ and $\mu d t+\sigma d w(t)$, respectively, where $r, \mu$, and $\sigma$ are constants and $w(t)$ is a standard Brownian motion in $R^{1}$.

The infinitely lived representative consumer has capital $W(t)$ at time $t$ denominated in units of the consumption good, investing fraction $\alpha(t), 0 \leq \alpha(t) \leq 1$, of the capital in the risky technology and the remaining fraction $1-\alpha(t)$ in the riskless technology. The consumer also consumes $c(t) d t$ in the period $[t, t+d t]$. Assume zero endowment flow and labor income. The increase in capital over $[t, t+d t]$ is

$$
d W(t)=\{[(\mu-r) \alpha(t)+r] W(t)-c(t)\} d t+\sigma \alpha(t) W(t) d w(t) .
$$

Given a consumption and investment policy, $\{c(t), \alpha(t), t \geq 0\}$, the expected utility of consumption from time 0 to infinity is defined as

$$
E_{0} \int_{0}^{\infty} e^{-\rho t} \gamma^{-1}[c(t)-x(t)]^{\gamma} d t
$$

where

$$
x(t) \equiv e^{-a t} x_{0}+b \int_{0}^{t} e^{a(s-t)} c(s) d s .
$$

Since $\lim _{\gamma \rightarrow 0} \gamma^{-1}\left(y^{\gamma}-1\right)=\ln y$, the case $\gamma \rightarrow 0$ in equation (2) corresponds to logarithmic utility, which may be treated separately rather than cluttering the notation by replacing $(c-x)^{\gamma}$ with $(c-x)^{\gamma}-1$.

The special case $x_{0}=b=0$ corresponds to time-separable utility with constant RRA, $1-\gamma$. The novel feature of the utility function studied in this paper is that the subsistence level of consumption, $x(t)$, is an exponentially weighted sum of past consumption. Thus utility is not time separable but exhibits habit persistence. The particular form of the habit-forming state variable, $x(t)$, defined in equation (3), was introduced by Ryder and Heal (1973), who studied a two-factor growth model maximizing expected utility $E_{0} \int_{0}^{\infty} e^{-\rho t} u(c(t), x(t)) d t$.

The utility function defined in equations (2) and (3) exhibits adjacent complementarity in consumption; that is, an increase in consumption increases the marginal utility of consumption at adjacent dates relative to the marginal utility of consumption at distant ones. Formally, define $J^{\prime}\left(c(\cdot), t_{1}\right)$ as the marginal utility of consumption at date $t_{1}$, where the derivative takes into account the impact of the change in $c\left(t_{1}\right)$ on all future values of $x(t)$. Define also the marginal rate of substitution between consumption at dates $t_{1}$ and $t_{2}, 0<t_{1}<t_{2}$, as $J^{\prime}\left(c(\cdot), t_{1}\right) / J^{\prime}\left(c(\cdot), t_{2}\right)$. By specializing the results of Ryder and Heal (1973), one can show that along a constant consumption path, $c(t)=$ 
$a x(t) / b=a x_{0} / b$, there exists a number $\bar{t}, t_{1}<\bar{t}<t_{2}$, such that the marginal rate of substitution increases when consumption $c(t)$ increases, for $t<\bar{t}$.

Theoretical and empirical tractability is the only reason why I model habit formation as in equations (2) and (3). My goal is not to study the most general utility function that exhibits habit persistence but rather to employ the simplest utility specification that resolves the equity premium puzzle.

The consumer's choice of a consumption and investment policy is restricted to the set of admissible policies defined by the following four properties: (i) The consumption and investment decisions taken at date $t$ are based solely on information available at date $t$. (ii) The consumption rate is nonnegative $(c(t) \geq 0)$, does not fall below the subsistence level $(c(t) \geq x(t))$, and results in finite total consumption over any horizon; that is, $\int_{0}^{t} c(s) d s<\infty$, for all $t$ almost surely. (iii) Investment in both technologies is nonnegative; that is, $0 \leq \alpha(t) \leq 1$ for all $t$ almost surely. (iv) The policy guarantees that the capital remains nonnegative; that is, $W(t) \geq 0$ for all $t$ almost surely.

An optimal admissible policy and the associated derived utility of capital are defined by

$$
V\left(W_{0}, x_{0}\right) \equiv \max _{\substack{\text { admisstble } \\ \alpha(s), c(s), s \geq 0\}}} E_{0} \int_{0}^{\infty} e^{-\rho s} \gamma^{-1}[c(s)-x(s)]^{\gamma} d s,
$$

where $W(0)=W_{0}$ and $x(0)=x_{0}$. I impose restrictions on the model parameters and motivate these restrictions.

Assume that

$$
1-\gamma>0, \quad \gamma \neq 0 .
$$

The case $\gamma=0$ corresponds to logarithmic utility and may be treated separately. Condition (5) is necessary if the RRA coefficient of the consumer is to be positive. As shown later, $1-\gamma$ is only approximately equal to the RRA coefficient. The equality is exact if utility is time separable, $b=0$, and is of the power form $x_{0}=0$.

Conditions (6) $-(8)$,

$$
\begin{gathered}
W_{0}>0, \\
W_{0}-\frac{x_{0}}{r+a-b}>0,
\end{gathered}
$$

and

$$
0<b<r+a,
$$


jointly imply that the set of admissible policies is nonempty. In particular, the policy $\{c(t)=(r+a-b) W(t), \alpha(t)=0, t \geq 0\}$ implies

$$
\begin{aligned}
W(t) & =W_{0} \exp [(b-a) t]>0, \\
c(t) & =(r+a-b) W_{0} \exp [(b-a) t]>0, \\
\int_{0}^{t} c(s) d s & <\infty, \\
c(t)-x(t) & =(r+a-b)\left(W_{0}-\frac{x_{0}}{r+a-b}\right) \exp (-a t)>0,
\end{aligned}
$$

thereby satisfying all the conditions of an admissible policy.

The condition

$$
\rho-\gamma r-\frac{\gamma(\mu-r)^{2}}{2(1-\gamma) \sigma^{2}}>0
$$

ensures that, under the optimal policy, the expected utility of consumption flow grows at a rate that is lower than the time preference, so that the expected utility of consumption over the infinite horizon is finite. It also implies that the appropriate transversality condition is satisfied.

Finally, assume that

$$
x_{0} \geq 0
$$

and

$$
0 \leq m \leq 1, \quad m \equiv \frac{\mu-r}{(1-\gamma) \sigma^{2}} .
$$

Conditions (5)-(11) are invoked in theorem 1 to prove that an optimal policy exists and is unique, and they lead to closed-form expressions for the optimal policy and for the derived utility of capital. Essentially, condition (10) guarantees that the condition $c(t) \geq 0$ of an admissible policy is nonbinding, and condition (11) guarantees that the condition $0 \leq \alpha(t) \leq 1$ of an admissible policy is nonbinding. Then the optimal consumption and investment are at an interior maximum, and this simplification leads to closed-form expressions.

\section{B. Optimal Consumption and Investment Policy}

In the first theorem I prove existence and uniqueness of an optimal policy, state the optimal policy, state the derived utility of capital, and state the dynamics of capital and consumption. 
THEOREM 1. Under conditions (5)-(11), an optimal admissible consumption and investment policy exists, is unique, and is given by

$$
c^{*}(t)=x(t)+h\left[W(t)-\frac{x(t)}{r+a-b}\right]
$$

and

$$
\alpha^{*}(t)=m\left[1-\frac{x(t) / W(t)}{r+a-b}\right]
$$

where

$$
h \equiv\left[\frac{r+a-b}{(r+a)(1-\gamma)}\right]\left[\rho-\gamma r-\frac{\gamma(\mu-r)^{2}}{2(1-\gamma) \sigma^{2}}\right]>0 .
$$

The derived utility of capital is

$$
V(W(t), x(t))=\frac{(r+a-b) h^{\gamma-1}}{(r+a) \gamma}\left[W(t)-\frac{x(t)}{r+a-b}\right]^{\gamma} .
$$

The capital is

$$
\begin{aligned}
W(t)= & \frac{x(t)}{r+a-b}+\left(W_{0}-\frac{x_{0}}{r+a-b}\right) \\
& \times \exp \left[\left(n-\frac{m^{2} \sigma^{2}}{2}\right) t+m \sigma \omega(t)\right],
\end{aligned}
$$

and the consumption growth rate is

$$
\frac{d c(t)}{c(t)}=\left[n+b-\frac{(n+a) x(t)}{c(t)}\right] d t+\left[1-\frac{x(t)}{c(t)}\right] m \sigma d w(t),
$$

where

$$
n \equiv \frac{r-\rho}{1-\gamma}+\frac{(\mu-r)^{2}(2-\gamma)}{2(1-\gamma)^{2} \sigma^{2}}
$$

The theorem is proved in Appendix A. Merton (1971) considered the special case $a=b=0$, which corresponds to time-separable utility with hyperbolic absolute risk aversion. He stated the optimal policy and proved its optimality and uniqueness. Sundaresan (1989) stated the optimal policy in two cases of nonseparable utility, $a=b$ and $a \gtrless$ $b$, but the direct utility exponential is $c-x$.

In addressing the equity premium puzzle, I interpret the optimal paths specified by theorem 1 as the equilibrium paths in a representative-consumer economy. In particular, the consumption growth rate, specified by equation (17), is interpreted as the per capita consump- 
tion growth rate. The mean and variance of the consumption growth rate are functions of the state variable $x(t)$, which appears as the ratio $z(t) \equiv x(t) / c(t)$. Theorem 2 states conditions under which this ratio has a stationary distribution and presents this distribution. This distribution is used to calculate the unconditional mean and variance of the consumption growth rate.

The RRA coefficient is defined in Section IIC and is shown to be a function of the state variable $x(t)$, which appears as the ratio $y(t) \equiv$ $x(t) /[c(t)-x(t)]=z(t) /[1-z(t)]$. Theorem 2 states conditions under which this ratio has a stationary distribution and presents this distribution and the mean of $y(t)$. This distribution is used to calculate the unconditional mean of the RRA coefficient.

Theorem 2. Assume that conditions (5)-(11) hold and also that

$$
n+a-b-m^{2} \sigma^{2}>0 .
$$

Then (i) $y(t) \equiv x(t) /[c(t)-x(t)]$ has a stationary probability distribution with density

$$
p_{y}(y)=k y^{-2(n+a-b) / m^{2} \boldsymbol{\sigma}^{2}} e^{-2 b / m^{2} \boldsymbol{\sigma}^{2} y}, \quad 0 \leq y<\infty,
$$

where

$$
k^{-1} \equiv\left(\frac{2 b}{m^{2} \sigma^{2}}\right)^{1-2(n+a-b) / m^{2} \sigma^{2}} \Gamma\left[\frac{2(n+a-b)}{m^{2} \sigma^{2}}-1\right]
$$

and $\Gamma(\cdot)$ is the gamma function. For the stationary distribution, $y$ has a single mode $\hat{y}$,

$$
\hat{y}=\frac{b}{n+a-b}<\infty
$$

and mean

$$
\bar{y}=\frac{b}{n+a-b-m^{2} \sigma^{2}}<\infty .
$$

(ii) $z(t) \equiv x(t) / c(t)$ has a stationary probability distribution with density

$$
\begin{gathered}
p_{z}(z)=k e^{2 b / m^{2} \boldsymbol{\sigma}^{2}}(1-z)^{2\left(n+a-b-m^{2} \boldsymbol{\sigma}^{2}\right) / m^{2} \boldsymbol{\sigma}^{2}} z^{2(b-a-n) / m^{2} \boldsymbol{\sigma}^{2}} e^{-2 b / m^{2} \boldsymbol{\sigma}^{2} z}, \\
0 \leq z<1 .
\end{gathered}
$$

For the stationary distribution, $z$ has a single mode $\hat{z}$,

$$
\hat{z}=\frac{n+a-\left[(n+a)^{2}-4 m^{2} \sigma^{2} b\right]^{1 / 2}}{2 m^{2} \sigma^{2}} .
$$


The proof is given in Appendix B. Using equation (17), we can calculate the unconditional mean and variance of the consumption growth rate as

$$
\frac{E(d c / c)}{d t}=n+b-(n+a) \int_{0}^{1} z p_{z}(z) d z
$$

and

$$
\frac{\operatorname{var}(d c / c)}{d t}=m^{2} \sigma^{2} \int_{0}^{1}(1-z)^{2} p_{z}(z) d z .
$$

The density $p_{z}(z)$ is given in theorem 2 , and the integration is done numerically since we are unable to obtain closed-form expressions for the integrals.

\section{A Wedge between the RRA Coefficient and the Inverse of the Intertemporal Elasticity of Substitution in Consumption}

I define the RRA coefficient and the intertemporal elasticity of substitution in consumption $(s)$. I show that the product $s \cdot$ RRA equals one in the time-separable model $(b=0)$ but is substantially below one in the nonseparable model and for the particular parameter values that resolve the equity premium puzzle. Thus habit persistence drives a wedge between the RRA coefficient and the inverse of the intertemporal elasticity of substitution in consumption.

I define the RRA coefficient in terms of an atemporal gamble that changes the current level of capital by the outcome of the gamble and is given by

$$
\operatorname{RRA}=\frac{-W V_{w w}}{V_{w}}=\frac{1-\gamma}{1-\{x(t) /[W(t)(r+a-b)]\}} .
$$

This definition is consistent with that in Giovannini and Weil (1988) for Kreps-Porteus preferences. In the context of an intertemporal model it would be improper to define the RRA coefficient in terms of an atemporal gamble that changes either current consumption or consumption at some specified future date by the outcome of the gamble.

The RRA coefficient is a function of wealth and of the state variable $x(t)$. A sudden drop in wealth leaves $x(t)$ unchanged in the short run and increases the RRA coefficient. This drop is only temporary because the RRA coefficient has a stationary distribution. To see this, we can use equation (12) to eliminate $W(t)$ from equation (28) and obtain

$$
\mathrm{RRA}=(1-\gamma)\left[1+\frac{h y(t)}{r+a-b}\right]
$$


The RRA coefficient has a steady-state distribution because $y(t)$ does, by theorem 2 . Since the mean value of $y(t)$ in the steady state is given by equation (23), we obtain the mean of the RRA coefficient as

$$
\overline{\operatorname{RRA}}=(1-\gamma)\left[1+\frac{h b}{(r+a-b)\left(n+a-b-m^{2} \sigma^{2}\right)}\right] .
$$

With the parameter values that resolve the equity premium puzzle, I show in Section III that the mean of the RRA coefficient is of the same order of magnitude as $1-\gamma$.

The elasticity of substitution in consumption is defined here as the derivative of the expected growth rate in consumption with respect to $r$, with $z(t), \mu-r$, and $\sigma^{2}$ held constant:

$$
\left.s \equiv \frac{\partial[E(d c / c) / d t]}{\partial r}\right|_{z(t), \mu-r, \mathbf{\sigma}^{2}}=\frac{1-z(t)}{1-\gamma} .
$$

Note that the elasticity may also be defined as the inverse of the expression $-c u_{c c} / u_{c}$. I stress, however, that this expression need not equal the RRA coefficient because risk aversion is defined in terms of an atemporal gamble that changes wealth and not in terms of a gamble that changes consumption.

We can combine equations (29) and (31) and write the product of the elasticity of substitution and the RRA coefficient as

$$
\begin{aligned}
s \cdot \mathbf{R R A} & =(1-z)\left(1+\frac{h y}{r+a-b}\right) \\
& =1-\left(1-\frac{h}{r+a-b}\right) z .
\end{aligned}
$$

To consider the special case of time-separable utility, let $b \rightarrow 0$. By equation (25) the modal value of $z$ tends to zero, and therefore the modal value of the product $s \cdot$ RRA tends to one. Note that we do not assume that $x_{0}=0$ or $a>0$; therefore $x(t)$ need not vanish as $b \rightarrow 0$. It is the assumption that utility is time separable, and not the stronger assumption that $x(t)$ vanishes, that gives the result that the product $s \cdot$ RRA has modal value one.

In his insightful exposition of growth theory, Solow (1970, p. 85) proved in the context of a deterministic growth model with timeseparable utility that the consumption growth rate is linear in the net marginal product of capital, with the coefficient equal to the inverse of the RRA coefficient. Put differently, the intertemporal elasticity of substitution in consumption is the inverse of the RRA coefficient. The assumption that consumption growth is deterministic is not crucial. Hansen and Singleton (1983), Breeden (1986), and Hall (1988) extended the result under uncertainty by making reasonable assump- 
tions about the stochastic process of consumption and the rates of return.

With habit persistence, the mode of the stationary distribution of $z$ is given by equation (25). In the next section I show that the modal value of $s \cdot$ RRA is substantially below one at the parameter values that resolve the equity premium puzzle.

Hansen and Singleton (1982, 1983), Ferson (1983), Grossman et al. (1987), and others rejected the Euler equation restriction implied by the time-separable model. Hall (1988) argued that since the timeseparable model forces the product $s$. RRA to equal one, these results are rejections of the Euler equation and the hypothesis that the product $s$ - RRA equals one. Ferson and Constantinides (1989) rejected the Euler equation implied by the time-separable model when the alternative hypothesis is the Euler equation implied by the nonseparable model. These results may be interpreted as evidence against the restriction $s \cdot \mathrm{RRA}=1$.

For the equilibrium of the particular model developed in this section, we may write the capital elasticity of consumption as

$$
\left.\frac{\partial c / c}{\partial W / W}\right|_{x}=s \cdot \operatorname{RRA}
$$

and the ratio of the standard deviation of the consumption growth rate and the capital growth rate as

$$
\frac{\operatorname{std}(d c / c)}{\operatorname{std}(d W / W)}=s \cdot \text { RRA. }
$$

Since habit persistence allows the product $s \cdot$ RRA to be substantially below one, we can conclude that habit persistence smooths consumption growth over and above the smoothing implied by the life cyclepermanent income hypothesis with time-separable utility.

\section{Resolution of the Equity Premium Puzzle}

I interpret the growth model developed in Section II as the equilibrium in a representative-consumer production economy. The optimal consumption path is interpreted as the per capita consumption.

Mehra and Prescott (1985) estimated the mean of the annual growth rate of per capita real consumption of nondurables and services in the years $1889-1978$ to be .0183 with a range $-.0025, .03$ in subperiods. They also estimated the standard deviation of the growth rate in the years $1889-1978$ to be .0357 with a range $.010, .0528$ in subperiods. In terms of our notation, we want the model stated in Section II to imply $E(d c / c) / d t=.0183$ per year and $\operatorname{var}(d c / c) / d t=$ $(.0357)^{2}$ per year. 
Mehra and Prescott estimated the mean annual real rate of return on a relatively riskless security to be .008 , using 90 -day Treasury bills in the 1931-78 period, Treasury certificates in the 1920-30 period, and 60-90-day prime commercial paper in the 1889-1920 period. Thus we can set $r=.01$ per year.

Let us introduce a firm that has capital $K(t)$ at time $t$. The firm has free access to the two production technologies. It invests capital $\delta_{1} K(t)$ in the risky technology and the remaining capital $\left(1-\delta_{1}\right) K(t)$ in the riskless technology, where $\delta_{1}$ is a constant, $0<\delta_{1} \leq 1$. The firm is financed with equity of value $S(t)$ and riskless debt of value $B(t)$. The firm maintains the ratio $S(t) /[S(t)+B(t)]=\delta_{2}$ constant, $0<\delta_{2} \leq 1$. Since the firm has free access to the constant-returns-to-scale technologies, the value of the firm equals its capital, that is, $S(t)+B(t)=$ $K(t)$. Since the bonds are riskless, their rate of return is $d B / B=r d t$. Denoting by $d S / S$ the rate of return on equity, we obtain

$$
d S(t)+B(t) r d t=\delta_{1} K(t)[\mu d t+\sigma d w(t)]+\left(1-\delta_{1}\right) K(t) r d t,
$$

which simplifies into

$$
\frac{d S(t)}{S(t)}=\left(\frac{\delta_{1}}{\delta_{2}}\right)[(\mu-r) d t+\sigma d w(t)]+r d t
$$

I interpret the equity of the firm as a portfolio of the stocks represented in the Standard and Poor's composite stock price index. Given the leverage $\left(\delta_{2}\right)$ of the firms represented in the index, the ratio $\delta_{1} / \delta_{2}$ is free in the range $0<\delta_{1} / \delta_{2} \leq \delta_{2}^{-1}$ since the parameter $\delta_{1}$ is free in the range $0<\delta_{1} \leq 1$. In our calculation, we can set $\delta_{1} / \delta_{2}=1$, which is consistent with any amount of leverage.

Mehra and Prescott estimated the annual real return on the Standard and Poor's composite stock price index in the 1889-1978 period to have mean .0698 (with range $-.0014, .1896$ in subperiods) and standard deviation .1654 (with range .002, .2790 in subperiods). These estimates are generally consistent with those by Ibbotson and Sinquefield (1982, p. 15). Thus we can set

$$
\frac{E(d S / S)}{d t}=\left(\frac{\delta_{1}}{\delta_{2}}\right)(\mu-r)=.06 \text { per year }
$$

and

$$
\frac{\operatorname{var}(d S / S)}{d t}=\left(\frac{\delta_{1}}{\delta_{2}}\right)^{2} \sigma^{2}=(.165)^{2} \text { per year. }
$$

The mean and variance of the consumption growth rate are independent of the ratio $\delta_{1} / \delta_{2}$. Equations (26) and (27) show that the mean and variance of the consumption growth rate depend on the parameters $\mu$ and $\sigma$ only in the combination $(\mu-r) / \sigma=.06 / .165$, which is 
independent of $\delta_{1} / \delta_{2}$. However, condition (11) requires $1-\gamma \geq$ $2.2\left(\delta_{1} / \delta_{2}\right)$.

In the context of the production economy, time-separable utility implies that the RRA coefficient equals 10.2 ; hence the equity premium puzzle. To see this, time-separable utility implies that $b \rightarrow 0$ and that the modal value of $z(t)$ is zero. Then

$$
\frac{\operatorname{var}(d c / c)}{d t}=m^{2} \sigma^{2}=\frac{(\mu-r)^{2}}{\sigma^{2}(1-\gamma)^{2}}=(.0357)^{2},
$$

which implies $1-\gamma=10.2$, irrespective of the ratio $\delta_{1} / \delta_{2}{ }^{1}$

I proceed to show that habit persistence can generate the sample mean and variance of the consumption growth rate with a low RRA coefficient. Let us set $\rho=.037$ per year, $1-\gamma=2.2$, and $\delta_{1} / \delta_{2}=1$. The reader may verify that these parameter values, together with the parameter values specified in equations (36) and (37), satisfy the model conditions (5), (9), and (11).

Let us consider pairs of parameter values $(a, b)$ that satisfy the conditions (8) and (19). For each pair $(a, b)$, the stationary distribution of $z$ is given by equation (24). We can calculate the mean and variance of the consumption growth rate by performing the numerical integration in equations (26) and (27). Table 1 reports pairs $(a, b)$ for which the mean and variance of the consumption growth rate match their sample estimates.

The table also reports the mean RRA coefficient. As one shifts to the right of the table, the mean RRA coefficient decreases and approaches the value $1-\gamma=2.2$. The equity premium puzzle is resolved in the sense that the model generates the mean and variance of the consumption growth rate with the mean RRA coefficient as low as 2.81 .

If the value of 2.81 is not sufficiently low relative to the reader's prior on the RRA coefficient, we can generate the target mean and variance of the consumption growth rate with a lower RRA coefficient by setting a lower value for $1-\gamma$. Now in order to satisfy the condition (11), we have to set $\delta_{1} / \delta_{2}>1$. If we assume that the firm has a debt/equity ratio equal to one, then $\delta_{2}=.5$ and we can set $\delta_{1} / \delta_{2}=2$

${ }^{1}$ Friend and Blume (1975) estimated the demand for risky assets and inferred the RRA coefficient to be well below 10 , under the assumption that the investment opportunity set is constant. Black (1988) and Kocherlakota (1988) pointed out that the Friend and Blume inference of the RRA coefficient is invalid if the investment opportunity set is not constant. An alternative source of estimates of the RRA coefficient, which does not rely on the assumption of a constant investment opportunity set, is based on the Euler equation implied by time-separable and non-time-separable utility functions. Typically, risk aversion is estimated to be well below 10 . Some of this literature is reviewed in Sec. V. 
TABLE 1

Mean and Variance of the Consumption Growth Rate Generated by the Model with Habit Persistence

\begin{tabular}{lllllll}
\hline \hline Parameter $a$, per year & .1 & .2 & .3 & .4 & .5 & .6 \\
Parameter $b$ & .093 & .172 & .250 & .328 & .405 & .492 \\
$\begin{array}{l}\text { Mode }(\hat{z}) \text { of the state } \\
\quad \text { variable } z\end{array}$ & .86 & .82 & .81 & .80 & .79 & .81 \\
$\begin{array}{l}\text { Mean annual growth } \\
\quad \text { rate in }\end{array}$ & & & & & & \\
$\quad \begin{array}{l}\text { consumption: } \\
\text { Unconditional mean }\end{array}$ & .018 & .019 & .018 & .018 & .018 & .018 \\
$\quad$ At $z=\hat{z}$ & .011 & .013 & .014 & .014 & .014 & .014 \\
$\begin{array}{l}\text { Standard deviation } \\
\quad \text { of the annual }\end{array}$ & & & & & & \\
$\quad \begin{array}{l}\text { growth rate in } \\
\quad \text { consumption: }\end{array}$ & & & & & & \\
$\quad \begin{array}{l}\text { Unconditional mean } \\
\text { At } z=\hat{z}\end{array}$ & .036 & .036 & .036 & .036 & .036 & .034 \\
RRA coefficient: & .023 & .029 & .032 & .033 & .034 & .032 \\
$\quad \begin{array}{l}\text { Unconditional mean } \\
\text { At } z=\hat{z}\end{array}$ & 8.67 & 4.37 & 3.47 & 3.09 & 2.88 & 2.81 \\
Elasticity of substi- & 7.03 & 4.09 & 3.36 & 3.03 & 2.84 & 2.78 \\
$\quad$ tution $(s)$ & & & & & & \\
$\quad$ at $z=\hat{z}$ & .06 & .08 & .09 & .09 & .09 & .09 \\
$s$ RRA at $z=\hat{z}$ & .42 & .33 & .30 & .27 & .26 & .25 \\
\hline
\end{tabular}

Note. - The assumed parameter values are $r=.01$, the annual rate of return of the riskless technology; $\mu-r=$ .06 , the difference between the mean annual rate of return of the risky technology and the annual rate of return of the riskless technology; $\sigma=.165$, the standard deviation of the annual rate of return of the risky technology; $\gamma=$ -1.2 , the power in the utility function; and $\rho=.037$, the rate of time preference in units (year) ${ }^{-1}$.

and $1-\gamma=1.1$. By judicious choice of parameters $(a, b)$, we can generate the target mean and variance of the consumption growth rate with the RRA coefficient close to 1.1.

An interesting feature of table 1 is that the modal value of the state variable $z(t)=x(t) / c(t)$ is about .8 for all the reported $(a, b)$ pairs. The model predicts that the subsistence level of consumption, $x(t)$, generated by habit persistence, is about 80 percent of the level of consumption. This prediction is discussed further in the last section. Another interesting feature of the table is that the intertemporal elasticity of substitution in consumption is substantially below one. Finally, the product of the elasticity of substitution and the RRA coefficient is about .25 for the pairs $(a, b)$ that resolve the equity premium puzzle with a low RRA coefficient. This illustrates the key role of habit persistence in resolving the puzzle by driving a wedge between the RRA coefficient and the inverse of the elasticity of substitution.

\section{Discussion}

We have resolved the equity premium puzzle by relaxing Mehra and Prescott's (1985) assumption that utility is time separable. However, 
our economy differs from theirs in two other respects as well. First, our economy allows for production while theirs is an exchange economy. Second, theirs is a discrete-time economy in which the state is a Markov process with two realizations, while ours is a continuous-time economy in which the forcing process is a diffusion. To make the case that habit persistence is the key to the puzzle, we need to demonstrate that these two differences in modeling the economy are inessential.

The first difference is inessential because, as Mehra and Prescott (1985) and Mehra (1988) pointed out, the task of explaining the puzzle in a production economy is not easier than in an exchange economy. The introduction of production does not increase the set of joint equilibrium processes on consumption and asset prices. In fact it may be harder to explain the puzzle in a production economy because the consumption process is no longer exogenous but must be obtained as the equilibrium outcome.

The second difference is inessential as well. I demonstrate that time separability in preferences is the key restriction that generates the puzzle in Mehra and Prescott's economy. Let $m_{t+1}$ be the marginal rate of substitution and $R_{F t}$ be the one-plus riskless rate of interest between periods $t$ and $t+1$. The Euler equation states that

$$
E\left(m_{t+1} R_{F t} \mid I_{t}\right)=1,
$$

where $I_{t}$ is the public information in period $t$. Since $R_{F t}$ is in the information set $I_{t}$, we can write $E\left(m_{t+1} \mid I_{t}\right)=R_{F t}^{-1}$ and, by Jensen's inequality, express the unconditional mean of the marginal rate of substitution as

$$
E(m)=E\left(R_{F}^{-1}\right) \geq\left[E\left(R_{F}\right)\right]^{-1} .
$$

Let equity have one-plus rate of return $R_{t+1}$. The Euler equation states that

$$
E\left(m_{t+1} R_{t+1} \mid I_{t}\right)=1
$$

and

$$
E(m R)=1 .
$$

Following the methodology of Hansen and Jagannathan (1988), we can write

$$
\begin{aligned}
1=E(m R) & =E(m) E(R)+\operatorname{cov}(m, R) \\
& \geq E(m) E(R)-\operatorname{std}(m) \operatorname{std}(R) \\
& \geq \frac{E(R)}{E\left(R_{F}\right)}-\operatorname{std}(m) \operatorname{std}(R)
\end{aligned}
$$


by equation (39) or

$$
\operatorname{std}(m) \geq \frac{\left[E(R) / E\left(R_{F}\right)\right]-1}{\operatorname{std}(R)} .
$$

Assume that utility is separable and of the form $\Sigma_{t=0}^{\infty} \beta^{t} \gamma^{-1} c_{t}^{\gamma}$. Then the marginal rate of substitution is $m_{t+1}=\beta\left(c_{t+1} / c_{t}\right)^{\gamma-1}$. Further assume that the consumption growth rate is bounded by

$$
g_{1} \leq \frac{c_{t+1}}{c_{t}} \leq g_{2}
$$

Then the marginal rate of substitution is bounded by

$$
\beta g_{2}^{\gamma-1} \leq m_{t+1} \leq \beta g_{1}^{\gamma-1},
$$

and its standard deviation is bounded by

$$
\operatorname{std}(m) \leq \frac{\beta g_{1}^{\gamma-1}-\beta g_{2}^{\gamma-1}}{2} .
$$

Combining inequalities (42) and (45), we obtain a lower bound on the RRA coefficient, $1-\gamma$, as

$$
\beta g_{1}^{\gamma-1}-\beta g_{2}^{\gamma-1} \geq \frac{2\left\{\left[E(R) / E\left(R_{F}\right)\right]-1\right\}}{\operatorname{std}(R)} .
$$

Mehra and Prescott's parameter estimates are $E\left(R_{F}\right)=1.01$ per year, $E(R)=1.07$ per year, and $\operatorname{std}(R)=.165$ per year. They assumed a two-state Markov process for the annual consumption growth rate. By the method of moments they estimated the annual consumption growth rate to be .982 or 1.054 . Thus we can set $g_{1}=$ .982 and $g_{2}=1.054$. Our restriction (46) on the RRA coefficient becomes

$$
.982^{\gamma-1}-1.054^{\gamma-1} \geq \frac{.72}{\beta} .
$$

For $\beta=.8$, the lower bound on the RRA coefficient $1-\gamma$ is greater than or equal to 16 ; for $\beta=.9,14$; for $\beta=1,12$; for $\beta=1.1,11$; and for $\beta=1.2,10$. The risk aversion is high, thereby illustrating the equity premium puzzle. Note that this conclusion is independent of the firm's leverage and of the correlation between consumption growth and the dividends on equity.

Essentially the lower bound on the consumption growth rate puts an upper bound on the marginal rate of substitution that is severe if utility is time separable. This causes the inability to explain the mean premium on equity returns. Rietz (1988) recognized the pivotal role of the lower bound on consumption growth. He proposed a model that allows for a disaster state, in which consumption may drop by as 
much as 25 percent in one year. The model generates sufficient variability in the marginal rate of substitution and explains the observed mean premium on equity. Mehra and Prescott (1988) responded that the existence of such disasters has testable, but empirically unobserved, economic implications at times of impending disaster, such as the period of the Cuban Missile Crisis.

A plausible explanation of the puzzle, suggested by Mehra and Prescott, is that consumers are heterogeneous and the market is incomplete. Bewley (1982), Mankiw (1986), Scheinkman and Weiss (1986), and Scheinkman (1989) presented models with uninsurable risks. They illustrated that an econometrician may grossly overestimate risk aversion based on per capita consumption. The individuals' consumption growth rate may be substantially more variable than the per capita growth rate. Even with low variability of per capita consumption, the individuals' marginal rate of substitution may be sufficiently variable to explain the observed mean premium on equity.

Brainard and Summers (1987) and Kocherlakota (1988) allowed the equity to be levered, and Kocherlakota allowed the subjective discount rate to be negative $(\rho<0$, i.e., $\beta>1)$. They found that the RRA coefficient must exceed 10 in order to generate the observed mean equity premium. This conclusion is consistent with the bounds on risk aversion derived in this section for time-separable utility.

Kocherlakota (1987) and Weil (1987) considered preferences that are not von Neumann-Morgenstern and found that the RRA coefficient must be high to explain the puzzle.

Nason (1988) generated the observed mean premium on equity by introducing state-nonseparable preferences in which the direct utility of consumption depends on past output. Whereas equilibrium consumption equals output in his model, the Euler equation and price paths are different from those implied by a direct utility function that depends on past consumption. One may view Nason's model as one in which utility exhibits habit persistence but the representative agent is myopic in that the agent disregards the effect of current consumption decisions on future utility.

The model in this paper generates the requisite high variability in the marginal rate of substitution in consumption with relatively low variability in the consumption growth rate through habit persistence in utility and low risk aversion. Essentially past consumption generates a subsistence level of consumption (which must be about 80 percent of the normal consumption rate in order to explain the mean equity premium, as in table 1). A small drop in consumption generates a large drop in consumption net of the subsistence level and a large drop in the marginal rate of substitution that makes it possible to match the observed equity premium with low risk aversion. 


\section{Concluding Remarks}

One prediction of habit persistence is that the subsistence rate of consumption is positive. For the particular parameter values that explain the observed mean premium on equity, the subsistence rate of consumption is about 80 percent of the recent past consumption rate.

Habit persistence and durability of goods are opposing effects in that habit persistence tends to make certain lag coefficients in the Euler equation negative while durability tends to reverse their signs. Dunn and Singleton (1986), Eichenbaum, Hansen, and Singleton (1988), Gallant and Tauchen (1989), and Eichenbaum and Hansen (in press) used monthly data and estimated positive coefficients that are interpreted as evidence of durability. However, Ferson and Constantinides (1989) used quarterly and annual data and estimated negative coefficients that are interpreted as evidence of habit persistence with the subsistence level of the predicted order of magnitude. Furthermore, they rejected the time-separable model in favor of the model with habit persistence. Hansen and Jagannathan (1988) also found evidence in favor of habit persistence, using monthly data. Finally, Heaton (1988) examined the monthly and quarterly autocorrelations in consumption, while taking into account time aggregation, and interpreted his results as evidence of habit persistence.

Habit persistence departs from the familiar paradigm of state- and time-separable preferences. To become the new economic paradigm, habit persistence ought to be embedded in models of the business cycle, labor behavior, public finance, and so forth with preferences, technologies, and dynamics richer than the ones introduced in this paper and its predictions validated by empirical testing.

\section{Appendix A}

\section{Proof of Theorem 1}

a) The proof employs a technique that is applied in a different context by Davis and Norman (1987). Assume that an optimal policy $\{c(s), \alpha(s), t \leq s\}$ is given by $c(s)=c^{*}(s)$ and $\alpha(s)=\alpha^{*}(s)$, where $c^{*}(s)$ and $\alpha^{*}(s)$ are defined in equations (12) and (13). I shall prove that the optimal admissible policy for $0 \leq s \leq t$ is unique and is also given by $c(s)=c^{*}(s)$ and $\alpha(s)=\alpha^{*}(s)$.

$b$ ) For $s \geq t$, the capital increase is

$$
d W(s)=\left\{\left[(\mu-r) \alpha^{*}(s)+r\right] W(s)-c^{*}(s)\right\} d s+\sigma \alpha^{*}(s) W(s) d w(s) .
$$

Also,

$$
d x(s)=\left[b c^{*}(s)-a x(s)\right] d s .
$$


Therefore,

$$
\begin{aligned}
d\left[W(s)-\frac{x(s)}{r+a-b}\right]= & \left\{\left[(\mu-r) \alpha^{*}(s)+r\right] W(s)-c^{*}(s)\right. \\
& \left.-\frac{b c^{*}(s)-a x(s)}{r+a-b}\right\} d s+\sigma \alpha^{*}(s) W(s) d w(s) \\
= & {\left[W(s)-\frac{x(s)}{r+a-b}\right][n d s+m \sigma d w(s)], }
\end{aligned}
$$

which implies

$$
d \ln \left[W(s)-\frac{x(s)}{r+a-b}\right]=\left(n-\frac{m^{2} \sigma^{2}}{2}\right) d s+m \sigma d w(s)
$$

with solution

$$
\begin{aligned}
W(s)-\frac{x(s)}{r+a-b}= & {\left[W(t)-\frac{x(t)}{r+a-b}\right] } \\
& \times \exp \left\{\left(n-\frac{m^{2} \sigma^{2}}{2}\right)(s-t)+m \sigma[w(s)-w(t)]\right\}, \quad s \geq t .
\end{aligned}
$$

For $s \geq t$,

$$
\begin{aligned}
& e^{-\rho(s-t)} E_{t}\left\{\left[c^{*}(s)-x(s)\right]^{\gamma}\right\} \\
&=h^{\gamma}\left[W(t)-\frac{x(t)}{r+a-b}\right]^{\gamma} \exp \left[-\rho(s-t)+\gamma\left(n-\frac{m^{2} \sigma^{2}}{2}\right)(s-t)\right] \\
& \times E_{t} \exp \{\gamma m \sigma[w(s)-w(t)]\} \\
&= h^{\gamma}\left[W(t)-\frac{x(t)}{r+a-b}\right]^{\gamma} \exp \left\{\left[-\rho+\gamma\left(n-\frac{m^{2} \sigma^{2}}{2}\right)+\frac{\gamma^{2} m^{2} \sigma^{2}}{2}\right](s-t)\right\} \\
&= h^{\gamma}\left[W(t)-\frac{x(t)}{r+a-b}\right]^{\gamma} \exp \left[-\frac{(r+a) h(s-t)}{r+a-b}\right]
\end{aligned}
$$

since

$$
\begin{aligned}
-\rho+\gamma\left(n-\frac{m^{2} \sigma^{2}}{2}\right)+\frac{\gamma^{2} m^{2} \sigma^{2}}{2} & =-\frac{1}{1-\gamma}\left[\rho-\gamma r-\frac{\gamma(\mu-r)^{2}}{2(1-\gamma) \sigma^{2}}\right] \\
& =-\frac{(r+a) h}{r+a-b} .
\end{aligned}
$$


Therefore,

$$
\begin{aligned}
V(W(t), x(t)) & =E_{t} \int_{t}^{\infty} e^{-\rho(s-t)} \gamma^{-1}\left[c^{*}(s)-x(s)\right]^{\gamma} d s \\
& =\frac{h^{\gamma}}{\gamma}\left[W(t)-\frac{x(t)}{r+a-b}\right]^{\gamma} \int_{t}^{\infty} \exp \left[-\frac{(r+a) h(s-t)}{r+a-b}\right] d s \\
& =\frac{(r+a-b) h^{\gamma-1}}{(r+a) \gamma}\left[W(t)-\frac{x(t)}{r+a-b}\right]^{\gamma}
\end{aligned}
$$

since $(r+a) h /(r+a-b)>0$. Note also that $V(W(t), x(t))$ is a $C^{2}$ function.

c) Define

$$
M(t) \equiv \int_{0}^{t} e^{-\rho s} \gamma^{-1}[c(s)-x(s)]^{\gamma} d s+e^{-\rho t} V(W(t), x(t))
$$

for an arbitrary policy $\{c(s), \alpha(s), 0 \leq s<t\}$. Applying Ito's lemma, we obtain $d M(t)=N(t) d t+e^{-\rho t} \alpha \sigma W V_{w} d w(t)$, where

$$
\begin{gathered}
N(t) \equiv e^{-\rho t}\left(\gamma^{-1}(c-x)^{\gamma}-\rho V+\{[(\mu-r) \alpha+r] W-c\} V_{w}\right. \\
\left.+\frac{\alpha^{2} \sigma^{2}}{2} W^{2} V_{w w}+(b c-a x) V_{x}\right) .
\end{gathered}
$$

Since $V_{w w}<0, N(t)$ is concave in $(c, \alpha)$. Suppressing momentarily the condition $0 \leq \alpha \leq 1$ and maximizing $N(t)$ with respect to $(c, \alpha)$, we obtain the first-order conditions that are necessary and sufficient:

$$
(c-x)^{\gamma-1}-V_{w}+b V_{x}=0
$$

and

$$
(\mu-r) W V_{w}+\alpha \sigma^{2} W^{2} V_{w w}=0
$$

Solving, we obtain

$$
c=x+h\left(W-\frac{x}{r+a-b}\right)=c^{*}
$$

and

$$
\alpha=m\left(1-\frac{x / W}{r+a-b}\right)=\alpha^{*} .
$$

Substituting $c^{*}(t)$ and $\alpha^{*}(t)$ in $N(t)$, we obtain $N(t)=0$. Therefore,

$$
\begin{aligned}
& d M(t) \leq e^{-\rho t} \alpha \sigma W V_{w} d w(t) \text { for arbitrary }(c, \alpha) \\
& =e^{-\rho t} \alpha \sigma W V_{w} d w(t) \text { for }\left(c=c^{*}, \alpha=\alpha^{*}\right),
\end{aligned}
$$

and $M(t)$ is a supermartingale. Thus

$$
E_{0} \int_{0}^{\infty} e^{-\rho s} \gamma^{-1}[c(s)-x(s)]^{\gamma} d s=E_{0} M(\infty) \leq E M(0)=V\left(W_{0}, x_{0}\right)
$$


with equality iff $c(s)=c^{*}(s)$ and $\alpha(s)=\alpha^{*}(s)$, for all $s, 0 \leq s$. Therefore, the optimal policy for $0 \leq s<t$ is unique and is given by $c(s)=c^{*}(s)$ and $\alpha(s)=$ $\alpha^{*}(s)$.

d) The policy $\left\{c^{*}(t), \alpha^{*}(t), t \geq 0\right\}$ obviously fulfills condition i of an admissible policy. It also fulfills condition ii. To see this, we proceed as in part $b$ and derive (A5). Since $W_{0}-\left[x_{0} /(r+a-b)\right]>0$, it follows that $W(t)-$ $[x(t) /(r+a-b)]>0$. Since $h>0$, it follows that $c(t)-x(t)>0$. Since $x_{0}>0$, then $c(0)>0, x(t)>0$, and $c(t)>0$. Finally, $\int_{0}^{t} c(s)<\infty$, for all $t$ almost surely.

The policy also fulfills condition iii of an admissible policy. Since $0 \leq m \leq 1$ and $0<1-\{[x(t) / W(t)] /(r+a-b)\}<1$, it follows that $0 \leq \alpha^{*}(t)<1$.

Finally, $W(t)>0$ since $W(t)-[x(t) /(r+a-b)]>0$. This fulfills the last condition of an admissible policy.

e) Under the optimal policy, equation (A8) gives the derived utility of capital as in equation (15). Equation (A5) gives the capital as in equation (16).

$f$ ) To find the consumption growth rate, we can use (A13) and (A5) to write

$$
\begin{aligned}
\ln (c-x)= & \ln h+\ln \left(W-\frac{x}{r+a-b}\right) \\
= & \ln h+\ln \left(W_{0}-\frac{x_{0}}{r+a-b}\right)+\left(n-\frac{m^{2} \sigma^{2}}{2}\right) t+m \sigma w(t), \\
& \frac{d c-d x}{c-x}=n d t+m \sigma d w(t), \\
\frac{d c}{c}= & \frac{1}{c}[d x+(c-x) n d t+(c-x) m \sigma d w(t)] \\
= & \frac{1}{c}[b c-a x+(c-x) n] d t+\left(1-\frac{x}{c}\right) m \sigma d w(t) \\
= & {\left[n+b-\frac{(n+a) x}{c}\right] d t+\left(1-\frac{x}{c}\right) m \sigma d w(t), }
\end{aligned}
$$

which proves (17).

\section{Appendix B}

\section{Proof of Theorem 2}

i) We can combine equations (3) and (17) and obtain the diffusion equation for $z$ as

$$
d z=\left[b-\left(n+a-m^{2} \sigma^{2}\right) z-m^{2} \sigma^{2} z^{2}\right](1-z) d t-z(1-z) m \sigma d w(t) .
$$

From (B1) we obtain the diffusion equation for $y=z /(1-z)$ as

$$
d y=\left[b-\left(n+a-b-m^{2} \sigma^{2}\right) y\right] d t-m \sigma y d w(t) .
$$

The forward, or Fokker-Planck, equation for the density $p_{y}\left(y(t) ; y_{0}, t\right), 0<t<$ $\infty$, is

$$
\frac{1}{2} \frac{\partial^{2}}{\partial y^{2}}\left(m^{2} \sigma^{2} y^{2} p_{y}\right)-\frac{\partial}{\partial y}\left\{\left[b-\left(n+a-b-m^{2} \sigma^{2}\right) y\right] p_{y}\right\}=\frac{\partial p_{y}}{\partial t} .
$$


This forward equation is a member of the class of forward equations studied by Wong (1964). Specializing the results of Wong for the problem at hand, we conclude that, for $0 \leq y<\infty$, the stationary distribution of $p_{y}(y)$ exists and is the solution of the Pearson equation

$$
\frac{1}{2} \frac{\partial}{\partial y}\left(m^{2} \sigma^{2} y^{2} p_{y}\right)-\left[b-\left(n+a-b-m^{2} \sigma^{2}\right) y\right] p_{y}=0
$$

subject to the normalization

$$
\int_{0}^{\infty} p_{y}(y) d y=1
$$

We rewrite equation (B4) as

$$
1 / 2 m^{2} \sigma^{2} y^{2} \frac{\partial}{\partial y} p_{y}-[b-(n+a-b) y] p_{y}=0 .
$$

The solution of equation (B6) is equation (20), and the normalizing constant $k$ is stated in terms of a gamma function in equation (21).

A mode, $\hat{y}$, of the stationary distribution satisfies $\partial p_{y} / \partial y=0$, and we obtain $b-(n+a-b) \hat{y}=0$ with unique solution given by equation (22). We integrate equation (B6) by parts and obtain

$$
1 / 2 m^{2} \sigma^{2}\left[y^{2} p_{y}\right]_{0}^{\infty}-m^{2} \sigma^{2} \int_{0}^{\infty} y p_{y} d y-b+(n+a-b) \int_{0}^{\infty} y p_{y} d y=0 .
$$

Inspection of equation (20) implies $y^{2} p_{y} \rightarrow 0$ as $y \rightarrow 0$. Also, condition (19) and equation (20) imply $y^{2} p_{y} \rightarrow 0$ as $y \rightarrow \infty$. Then equation (B7) gives the mean value of $y$ as in equation (23). Condition (19) guarantees that the mean is finite.

ii) Since $z=y /(1+y)$ and $0 \leq y<\infty$, it follows that $z$ is monotone increasing in $y$ in the domain of $y$ and $0 \leq z<1$. Since $y(t)$ has a stationary distribution, so does $z(t)$. The density of the stationary distribution of $z$ is $p_{z}(z)$ :

$$
p_{z}(z)=p_{y}(y) \frac{d y}{d z}=(1-z)^{-2} p_{y}\left(\frac{z}{1-z}\right) .
$$

Combining equations (B8) and (20), we obtain equation (24).

If $\hat{z}$ is a mode of the stationary distribution, it must satisfy $\partial p_{z}(z) / \partial z=0$, which, on simplification, becomes

$$
m^{2} \sigma^{2} \hat{z}^{2}-(n+a) \hat{z}+b=0 .
$$

The left-hand side of (B9) equals $b>0$ at $\hat{z}=0$ and $m^{2} \sigma^{2}-n-a+b<0$ at $\hat{z}=1$. Therefore, the quadratic has only one root in the range $0 \leq \hat{z} \leq 1$. The stationary distribution has a single mode at $\hat{z}$ given by equation (25). This completes the proof.

\section{References}

Becker, Gary S., and Murphy, Kevin M. "A Theory of Rational Addiction." J.P.E. 96 (August 1988): 675-700. 
Bewley, Truman F. "Thoughts on Tests of the Intertemporal Asset Pricing Model.” Manuscript. Evanston, Ill.: Northwestern Univ., 1982.

Black, Fischer. "Noise." J. Finance 41 (July 1986): 529-43.

. "Mean Reversion and Consumption Smoothing." Manuscript. New York: Goldman, Sachs, 1988.

Brainard, William, and Summers, Lawrence H. "Leverage and the Equity Premium Puzzle." Manuscript. New Haven, Conn.: Yale Univ., 1987.

Breeden, Douglas T. "Consumption, Production, Inflation and Interest Rates: A Synthesis." J. Financial Econ. 16 (May 1986): 3-39.

Campbell, John Y., and Kyle, Albert S. "Smart Money, Noise Trading and Stock Price Behavior.” Manuscript. Princeton, N.J.: Princeton Univ., 1988.

Campbell, John Y., and Shiller, Robert J. "Stock Prices, Earnings, and Expected Dividends." J. Finance 43 (July 1988): 661-76.

Davis, Mark H. A., and Norman, Andrew R. "Portfolio Selection with Transaction Costs." Manuscript. London: Imperial Coll., 1987.

Deaton, Angus. "Consumers' Expenditure." In The New Palgrave: A Dictionary of Economics, edited by John Eatwell, Murray Milgate, and Peter Newman. London: Macmillan, 1987.

De Long, J. Bradford; Shleifer, Andrei; Summers, Lawrence H.; and Waldmann, Robert J. "Noise Trader Risk in Financial Markets." J.P.E. 98 (August 1990), in press.

Duesenberry, James S. Income, Saving, and the Theory of Consumer Behavior. Cambridge, Mass.: Harvard Univ. Press, 1949

Dunn, Kenneth B., and Singleton, Kenneth J. "Modeling the Term Structure of Interest Rates under Non-separable Utility and Durability of Goods." J. Financial Econ. 17 (September 1986): 27-55.

Eichenbaum, Martin S., and Hansen, Lars Peter. "Estimating Models with Intertemporal Substitution Using Aggregate Time Series Data." J. Bus. and Econ. Statis. (in press).

Eichenbaum, Martin S.; Hansen, Lars Peter; and Singleton, Kenneth J. "A Time Series Analysis of Representative Agent Models of Consumption and Leisure Choice under Uncertainty." Q.J.E. 103 (February 1988): 51-78.

Ferson, Wayne E. "Expectations of Real Interest Rates and Aggregate Consumption: Empirical Tests." J. Financial and Quantitative Analysis 18 (December 1983): 477-97.

Ferson, Wayne E., and Constantinides, George M. "Habit Persistence and Durability in Aggregate Consumption: Empirical Tests." Manuscript. Chicago: Univ. Chicago, 1989.

Friend, Irwin, and Blume, Marshall E. "The Demand for Risky Assets." A.E.R. 65 (December 1975): 900-922.

Gallant, A. Ronald, and Tauchen, George. "Seminonparametric Estimation of Conditionally Constrained Heterogeneous Processes: Asset Pricing Applications." Manuscript. Durham, N.C.: Duke Univ., 1989.

Giovannini, Alberto, and Weil, Philippe. "Risk Aversion and Intertemporal Substitution in the Capital Asset Pricing Model." Manuscript. Cambridge, Mass.: NBER, 1988.

Grossman, Sanford J.; Melino, Angelo; and Shiller, Robert J. "Estimating the Continuous-Time Consumption-based Asset-Pricing Model." J. Bus. and Econ. Statis. 5 (July 1987): 315-27.

Hall, Robert E. "Intertemporal Substitution in Consumption." J.P.E. 96 (April 1988): 339-57.

- "Consumption." In Modern Business Cycle Theory, edited by Robert J. Barro. Cambridge, Mass.: Harvard Univ. Press, 1989. 
Hansen, Lars Peter, and Jagannathan, Ravi. "Restrictions on Intertemporal Marginal Rates of Substitution Implied by Asset Prices." Manuscript. Chicago: Univ. Chicago, 1988.

Hansen, Lars Peter, and Singleton, Kenneth J. "Generalized Instrumental Variables Estimation of Nonlinear Rational Expectations Models." Econometrica 50 (September 1982): 1269-86.

- "Stochastic Consumption, Risk Aversion, and the Temporal Behavior of Asset Returns." J.P.E. 91 (April 1983): 249-65.

Heaton, John. "The Interaction between Time-Nonseparable Preferences and Time Aggregation." Manuscript. Chicago: Univ. Chicago, 1988.

Ibbotson, Roger G., and Sinquefield, Rex A. Stocks, Bonds, Bills and Inflation: The Past and the Future. Charlottesville, Va.: Financial Analysts Res. Found., 1982.

Kocherlakota, Narayana R. "State Nonseparability: Theory and Empirical Implications.” Ph.D. dissertation, Univ. Chicago, 1987.

- "In Defense of the Time and State Separable Utility-based AssetPricing Model.” Manuscript. Evanston, Ill.: Northwestern Univ., 1988.

Kydland, Finn E., and Prescott, Edward C. "Time to Build and Aggregate Fluctuations." Econometrica 50 (November 1982): 1345-70.

Lucas, Robert E., Jr. "Asset Prices in an Exchange Economy." Econometrica 46 (November 1978): 1429-45.

Mankiw, N. Gregory. "The Equity Premium and the Concentration of Aggregate Shocks." J. Financial Econ. 17 (September 1986): 211-19.

Mankiw, N. Gregory; Romer, David; and Shapiro, Matthew D. "An Unbiased Reexamination of Stock Market Volatility." J. Finance 40 (July 1985): 67787.

Marshall, Alfred. Principles of Economics: An Introductory Volume. 8th ed. London: Macmillan, 1920.

Mehra, Rajnish. "On Asset Prices in Exchange and Production Economies." Working Paper no. 1914-87. Cambridge: Massachusetts Inst. Tech., March 1988.

Mehra, Rajnish, and Prescott, Edward C. "The Equity Premium: A Puzzle." $J$. Monetary Econ. 15 (March 1985): 145-61.

- "The Equity Risk Premium: A Solution?" J. Monetary Econ. 22 (July 1988): 133-36.

Merton, Robert C. "Optimum Consumption and Portfolio Rules in a Continuous-Time Model.” J. Econ. Theory 3 (December 1971): 373-413.

Nason, James M. "The Equity Premium and Time-varying Risk Behavior." Manuscript. Washington: Fed. Reserve Board, 1988.

Pollak, Robert A. "Habit Formation and Dynamic Demand Functions." J.P.E. 78, no. 4, pt. 1 (July/August 1970): 745-63.

Rietz, Thomas A. "The Equity Risk Premium: A Solution." J. Monetary Econ. 22 (July 1988): 117-31.

Roll, Richard. " $R^{2}$." J. Finance 43 (July 1988): 541-66.

Ryder, Harl E., Jr., and Heal, Geoffrey M. "Optimum Growth with Intertemporally Dependent Preferences.” Rev. Econ. Studies 40 (January 1973): 133.

Scheinkman, José A. "Market Incompleteness and the Equilibrium Valuation of Assets." In Theory of Valuation: Frontiers of Modern Financial Theory, vol. 1, edited by George M. Constantinides and Sudipto Bhattacharya. Totowa, N.J.: Rowman and Littlefield, 1989.

Scheinkman, José A., and Weiss, Laurence. "Borrowing Constraints and Aggregate Economic Activity." Econometrica 54 (January 1986): 23-45. 
Solow, Robert M. Growth Theory: An Exposition. New York: Oxford Univ. Press, 1970.

Stigler, George J., and Becker, Gary S. "De Gustibus Non Est Disputandum." A.E.R. 67 (March 1977): 76-90.

Sundaresan, Suresh M. "Intertemporally Dependent Preferences and the Volatility of Consumption and Wealth." Rev. Financial Studies 2, no. 1 (1989): 73-89.

Weil, Philippe. "Asset Prices with Non-expected Utility Preferences." Manuscript. Cambridge, Mass.: Harvard Univ., 1987.

West, Kenneth D. "Bubbles, Fads and Stock Price Volatility Tests: A Partial Evaluation." J. Finance 43 (July 1988): 639-56. (a)

- "Dividend Innovations and Stock Price Volatility." Econometrica 56 (January 1988): 37-61. (b)

Wong, Eugene. "The Construction of a Class of Stationary Markoff Processes." In Proceedings of Symposia in Applied Mathematics, vol. 16. Providence, R.I.: American Math. Soc., 1964. 
http://www.jstor.org

\section{LINKED CITATIONS}

- Page 1 of 3 -

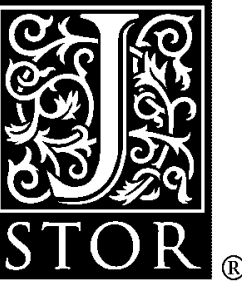

You have printed the following article:

Habit Formation: A Resolution of the Equity Premium Puzzle

George M. Constantinides

The Journal of Political Economy, Vol. 98, No. 3. (Jun., 1990), pp. 519-543.

Stable URL:

http://links.jstor.org/sici??sici=0022-3808\%28199006\%2998\%3A3\%3C519\%3AHFAROT\%3E2.0.CO\%3B2-T

This article references the following linked citations. If you are trying to access articles from an off-campus location, you may be required to first logon via your library web site to access JSTOR. Please visit your library's website or contact a librarian to learn about options for remote access to JSTOR.

\section{References}

\section{Noise}

Fischer Black

The Journal of Finance, Vol. 41, No. 3, Papers and Proceedings of the Forty-Fourth Annual Meeting of the America Finance Association, New York, New York, December 28-30, 1985. (Jul., 1986), pp. 529-543.

Stable URL:

http://links.jstor.org/sici?sici=0022-1082\%28198607\%2941\%3A3\%3C529\%3AN\%3E2.0.CO\%3B2-9

\section{Stock Prices, Earnings, and Expected Dividends}

John Y. Campbell; Robert J. Shiller

The Journal of Finance, Vol. 43, No. 3, Papers and Proceedings of the Forty-Seventh Annual Meeting of the American Finance Association, Chicago, Illinois, December 28-30, 1987. (Jul., 1988), pp. 661-676.

Stable URL:

http://links.jstor.org/sici?sici=0022-1082\%28198807\%2943\%3A3\%3C661\%3ASPEAED\%3E2.0.CO\%3B2-1

\section{Generalized Instrumental Variables Estimation of Nonlinear Rational Expectations Models}

Lars Peter Hansen; Kenneth J. Singleton

Econometrica, Vol. 50, No. 5. (Sep., 1982), pp. 1269-1286.

Stable URL:

http://links.jstor.org/sici?sici=0012-9682\%28198209\%2950\%3A5\%3C1269\%3AGIVEON\%3E2.0.CO\%3B2-G 
http://www.jstor.org

\section{LINKED CITATIONS}

- Page 2 of 3 -

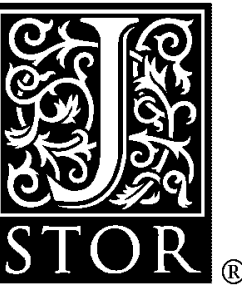

\section{Time to Build and Aggregate Fluctuations}

Finn E. Kydland; Edward C. Prescott

Econometrica, Vol. 50, No. 6. (Nov., 1982), pp. 1345-1370.

Stable URL:

http://links.jstor.org/sici?sici=0012-9682\%28198211\%2950\%3A6\%3C1345\%3ATTBAAF\%3E2.0.CO\%3B2-E

\section{Asset Prices in an Exchange Economy}

Robert E. Lucas, Jr.

Econometrica, Vol. 46, No. 6. (Nov., 1978), pp. 1429-1445.

Stable URL:

http://links.jstor.org/sici?sici=0012-9682\%28197811\%2946\%3A6\%3C1429\%3AAPIAEE\%3E2.0.CO\%3B2-I

\section{An Unbiased Reexamination of Stock Market Volatility}

N. Gregory Mankiw; David Romer; Matthew D. Shapiro

The Journal of Finance, Vol. 40, No. 3, Papers and Proceedings of the Forty-Third Annual Meeting American Finance Association, Dallas, Texas, December 28-30, 1984. (Jul., 1985), pp. 677-687.

Stable URL:

http://links.jstor.org/sici?sici=0022-1082\%28198507\%2940\%3A3\%3C677\%3AAUROSM\%3E2.0.CO\%3B2-M

\section{R2}

Richard Roll

The Journal of Finance, Vol. 43, No. 3, Papers and Proceedings of the Forty-Seventh Annual Meeting of the American Finance Association, Chicago, Illinois, December 28-30, 1987. (Jul., 1988), pp. 541-566.

Stable URL:

http://links.jstor.org/sici?sici=0022-1082\%28198807\%2943\%3A3\%3C541\%3A\%3E2.0.CO\%3B2-N

\section{Optimal Growth with Intertemporally Dependent Preferences}

Harl E. Ryder, Jr.; Geoffrey M. Heal

The Review of Economic Studies, Vol. 40, No. 1. (Jan., 1973), pp. 1-31.

Stable URL:

http://links.jstor.org/sici?sici=0034-6527\%28197301\%2940\%3A1\%3C1\%3AOGWIDP\%3E2.0.CO\%3B2-4

\section{Borrowing Constraints and Aggregate Economic Activity}

Jose A. Scheinkman; Laurence Weiss

Econometrica, Vol. 54, No. 1. (Jan., 1986), pp. 23-45.

Stable URL:

http://links.jstor.org/sici?sici=0012-9682\%28198601\%2954\%3A1\%3C23\%3ABCAAEA\%3E2.0.CO\%3B2-0 
http://www.jstor.org

\section{LINKED CITATIONS \\ - Page 3 of 3 -}

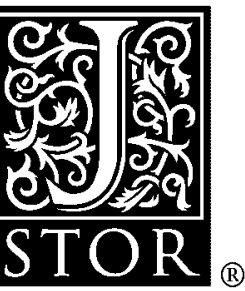

Intertemporally Dependent Preferences and the Volatility of Consumption and Wealth Suresh M. Sundaresan

The Review of Financial Studies, Vol. 2, No. 1. (1989), pp. 73-89.

Stable URL:

http://links.jstor.org/sici?sici=0893-9454\%281989\%292\%3A1\%3C73\%3AIDPATV\%3E2.0.CO\%3B2-A

\section{Bubbles, Fads and Stock Price Volatility Tests: A Partial Evaluation}

Kenneth D. West

The Journal of Finance, Vol. 43, No. 3, Papers and Proceedings of the Forty-Seventh Annual Meeting of the American Finance Association, Chicago, Illinois, December 28-30, 1987. (Jul., 1988), pp. 639-656.

Stable URL:

http://links.jstor.org/sici?sici=0022-1082\%28198807\%2943\%3A3\%3C639\%3ABFASPV\%3E2.0.CO\%3B2-8

\section{Dividend Innovations and Stock Price Volatility}

Kenneth D. West

Econometrica, Vol. 56, No. 1. (Jan., 1988), pp. 37-61.

Stable URL:

http://links.jstor.org/sici?sici=0012-9682\%28198801\%2956\%3A1\%3C37\%3ADIASPV\%3E2.0.CO\%3B2-M 